University of Wollongong

Research Online

Faculty of Engineering and Information

Faculty of Engineering and Information

Sciences - Papers: Part A

Sciences

$1-1-2012$

Exploring technological-organizational and environmental characteristics related to RFID adoption intention in the Saudi Arabia's retail industry

Salem Alqahtani

University of Wollongong, sa429@uowmail.edu.au

Samuel Fosso Wamba

University of Wollongong, samuel.fosso.wamba@neoma-bs.fr

Follow this and additional works at: https://ro.uow.edu.au/eispapers

Part of the Engineering Commons, and the Science and Technology Studies Commons

Research Online is the open access institutional repository for the University of Wollongong. For further information contact the UOW Library: research-pubs@uow.edu.au 


\title{
Exploring technological-organizational and environmental characteristics related to RFID adoption intention in the Saudi Arabia's retail industry
}

\author{
Abstract \\ Drawing on the diffusion of innovation (DOI) theory as well as on the emerging literature on RFID \\ technology, this study explores a set of technological, organizational and environmental characteristics \\ that will play an important role in the RFID adoption decision process within the Saudi retail industry. \\ Results of data collected among seven (7) Saudi large-scale retailers are presented and discussed, \\ together with the implications for research and practice.
}

\section{Keywords}

saudi, exploring, arabia, technological, retail, industry, organizational, environmental, characteristics, related, rfid, adoption, intention

Disciplines

Engineering | Science and Technology Studies

\section{Publication Details}

Alqahtani, S. \& Fosso Wamba, S. (2012). Exploring technological-organizational and environmental characteristics related to RFID adoption intention in the Saudi Arabia's retail industry. IEEE International Conference on RFID-Technology and Applications (pp. 1-6). Australia: IEEE. 


\section{Exploring Technological-Organizational and Environmental Characteristics Related to RFID Adoption Intention in the Saudi Arabia's Retail Industry}

\author{
Salem Alqahtani, Ph.D. Student \\ Wollongong University, Wollongong, Australia
}

\author{
Samuel Fosso Wamba, Ph.D. and IEEE Member \\ Wollongong University, Wollongong, Australia \\ Rouen Business School, Rouen, France
}

\begin{abstract}
Drawing on the diffusion of innovation (DOI) theory as well as on the emerging literature on RFID technology, this study explores a set of technological, organizational and environmental characteristics that will play an important role in the RFID adoption decision process within the Saudi retail industry. Results of data collected among seven (7) Saudi large-scale retailers are presented and discussed, together with the implications for research and practice.
\end{abstract}

Keywords; RFID technology; Saudi Arabia; Retail industry; DOI.

\section{INTRODUCTION}

For some time now, radio frequency identification (RFID), a wireless automatic identification and data capture (AIDC) technology [1], has been emerging as an open IT innovation [2] that can radically transform the retail industry. Indeed, the technology has the capability to collect data and automatically identify objects moving along a given supply chain [3]; and as a result, it can facilitate end-to-end retail operations through real-time access to information, intra- and inter-business processes automation, real-time tracking and tracing of items as they are moving along the retail supply chain $[1,4]$, as well as the decision making process. Despite these high operational and strategic potentials of RFID technology, very few studies have been conducted on the technological-organizational and environmental characteristics related to RFID adoption intention in retail industry in Saudi Arabia, the largest Arab country of the Middle East. Therefore, this study appears as an initial step towards bridging this knowledge gap in the literature. More specifically, this study see to draw on both the diffusion-ofinnovation theory and the extant literature on RFID technology to examine the following research question: What are the technological-organizational and environmental characteristics related to RFID adoption intention in the Saudi retail industry?

The remainder of this paper is structured as follows: Section 2 introduces the retail industry in Saudi Arabia; then Section 3 presents the supply chain management technology, followed by Section 4 on IT adoption. Section 5 describes our methodology and results, while Section 6 presents discussions. Finally, Section 7 serves as the conclusion.

\section{RETAIL INDUSTRY IN SAUDI ARABIA}

\section{A. Saudi Arabia: Social and political contexts}

Saudi Arabia - or The Kingdom of Saudi Arabia - is considered as the largest Arab country of the Middle East. The country features among the leading producers of oil and natural gas. Saudi Arabia is one of the most conservative countries in the World, where all cultural, social and political aspects of the society are organized around the Islamic and Arabic principles and cultural values on the one hand, and the Shari'a law on the other hand. Recently, however, the Saudi authorities have been promoting the use of IT innovation to improve some aspects of the society including the use of ecommerce and e-government principles and technologies for competitive advantage $[5,6]$.

\section{B. The Saudi retail industry}

The retail industry is one of the largest sectors in Saudi Arabia. Some analysts estimate the Saudi sales were $\$ 76$ billion in 2009, and will reach almost \$ 129 billion in 2014 [7]. In addition, Saudi retail firms, like many other firms in the Kingdom, are not subject to income taxes; however, their financial information is not made available to the public.

\section{SupPly Chain MANAGEMENT TECHNOLOGIES}

The issue of supply chain design and management (SCM) has become important to the framework of operations, and especially with the development of information and communication technologies (ICTs), such as the electronic data interchange (EDI) and the Internet. They are used to minimize the depth and complexity of the systems driving buyer-supplier relationships. SCM seems so complex that companies would rather focus on online communication systems, like the Internet, to heighten communication between people, businesses, and consumers [8]. Moreover, the role of the Internet in the development of successful commercial supply chains is essential to the challenge of online businesses [9].

According to Patterson et al. [10], in order to understand the issue of acceptance and implementation of supply chain technology, a technology adoption score needs to be calculated for each company; and this is possible through the calculation of the average of responses across a range of thirteen functional technologies and two integrative 
technologies. The radio frequency system is the one of these technologies.

Supply chain technologies imply that the implementation of standardized data forms and information sharing can be improved, along with the influence of the supply chain partners who are responsible for aligning transactions and enhancing inter-firm communication.

\section{IT ADOPTION: THE CASE OF RFID TECHNOLOGY}

Technology diffusion is deployed from the top executive level to a broader application, or is demanded by users, who need administrative support [11]. A top down approach for the greater part supports RFID technology diffusion across a range of industries, because of inexperience for the technology. However, for the various industries, including automotive, chemical, and manufacturing companies for high-priced goods, the use of RFID is seen as considerably advantageous, despite the potentially high costs and errors generated. With regard to RFID technology, the adoption and/or diffusion model is based on whether RFID can pursue the technology/innovation decision process, which is based on knowledge, persuasion, decision, and confirmation [11]. Government has supported a significant portion of the technology adoption and retail mandates in manufacturing [12].

In this research study, the DOI theory is used as the theoretical background, as its is recognized by many scholars as a relevant theory to study the adoption intention of potential adopters of a given innovation [11]. The DOI scholars have identified a set of characteristics impacting the intention to adopt IT innovations; they include innovation characteristics (e.g., relative advantage, compatibility, complexity), organizational characteristics (e.g., top management, organization size) and environmental characteristics (e.g., competitive pressure, government regulation) [11].

\section{METHODOLOGY}

In this study, a mixed methodology was used. More specifically, a case study using interview was used in the first phase, followed by a survey study in the second phase. Seven (7) Saudi large-scale retailers from Riyadh, Jeddah and Dammam were involved in this study. Data collection comprised interviews, document analysis, and a paper-based questionnaire. All items of technological-organizational and environmental characteristics related to the intention to adopt RFID technology were measured using a five-point Likert scale, from 1 (strongly disagree) to 5 (strongly agree). Furthermore, we have adopted an approach similar to the one used by [13], while bounding our study to a set of technological, organizational and environmental characteristics.

\section{QUANTITATIVE DATA ANALYSIS AND DISCUSSION}

Descriptive statistics are used to describe and present quantitative data in this study.

\section{A. Business association of the survey respondents}

In this research, the response rate is $51 \%$ from the 110 questionnaires that were distributed, 56 of which were identified as being correctly filled out and therefore suitable for analysis. Among the respondents, 84\% were working in Hypermarkets, while $16 \%$ were operating in the retail sector as business associations (see Fig. 1). On the other hand, it is clear that our sample is dominated by the Hypermarket.



FIGURE 1. BUSINESS ASSOICATION

\section{B. The level of RFID knowledge of the survey respondents}

From Fig. 2, we can see that $48 \%$ of respondents claimed to have a poor knowledge of RFID, while $43 \%$ had a good knowledge of the same technology. Furthermore, 5\% of respondents claimed to have a very good knowledge of RFID, and by contrast, $4 \%$ of respondents indicated that they had a very poor knowledge of RFID. Overall, the vast majority of respondents had very little knowledge of RFID technology.

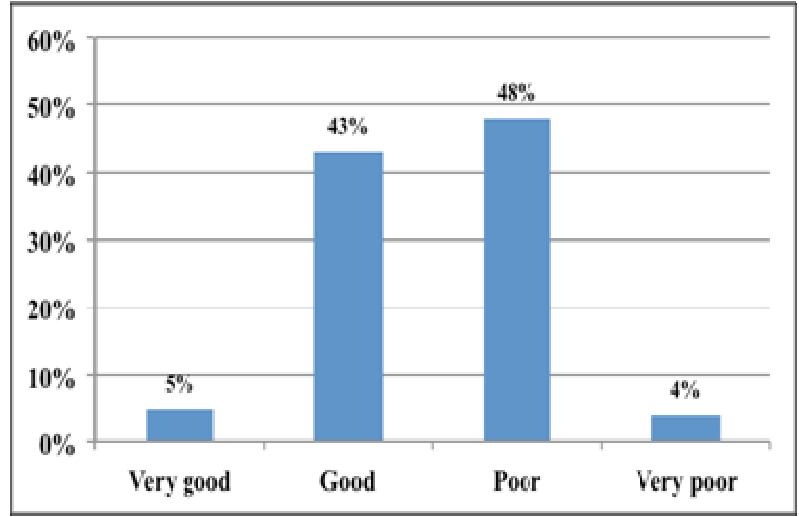

FIGURE 2. THE LEVEL OF KNOWLEDGE REGARDING RFID

\section{Involvement time of survey respondents in RFID project}

Based on data collection, only $3.6 \%$ of respondents were been working with RFID for 2 to 5 years. In addition, $1.8 \%$ of respondents were involved in RFID projects for 1 to 2 years, while the vast majority of respondents $(92.8 \%)$ had not been involved in any RFID project. However, there were also those with more than 5 years' experience $(1.8 \%)$ as indicated in Fig. 3 . 




FIGURE 3. TIME OF RFID PROJECT

\section{Location of the survey respondents' headquarters}

Participants were from organizations with headquarters in three different areas, namely Riyadh, Jeddah and Dammam. Fig. 4 shows that half of participants were from Riyadh $(50 \%$ or 28 respondents), $32 \%$ (18 respondents) from Jeddah, and $18 \%$ (10 respondents) from Dammam.



FIGURE 4. THE LOCATION OF PARTICIPANTS

\section{E. Technological Characteristics}

In this section, the following RFID technological characteristics were assessed: RFID relative advantage, RFID complexity, and RFID compatibility. The mean was applied as a measure of central tendency, which indicated that all variables were above their midpoint level, as indicated in Fig. 5 . There are nine items under relative advantage. The improved product security was the highest rating item $(\mathrm{M}=4.18)$, while the improved lower inventory cost was the lowest rating $(\mathrm{M}=3.84)$.

Moreover, there were seven items under the complexity of RFID with the highest customization scoring in the rating $(\mathrm{M}=3.75)$, while the vast amount of data as a big challenge had the lowest score in rating $(\mathrm{M}=3.36)$.

Furthermore, RFID compatibility had five items. RFID compatibility with the hardware and software available in the surveyed companies had the highest rating $(\mathrm{M}=3.82)$. Meanwhile, RFID compatibility with the existing information infrastructure in the surveyed companies was the lowest item in the rating $(M=2.71)$.

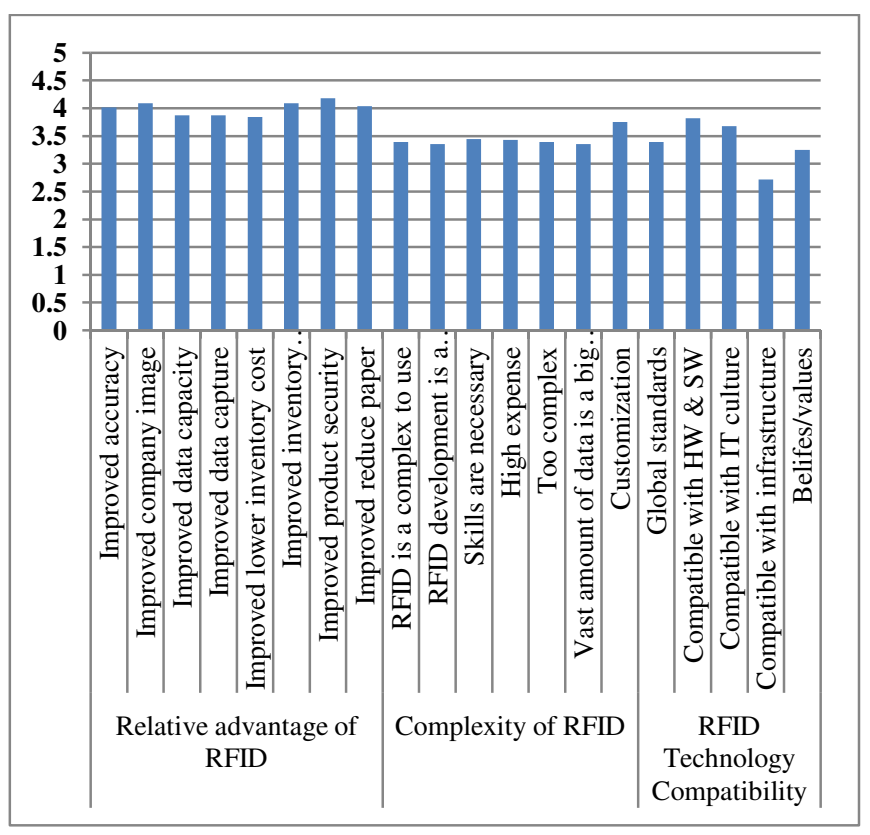

Figure 5. TeChNological Characteristics

\section{F. Organizational Characteristics}

The following organizational characteristics were assessed: technology competence, top management support, and organization size. There were three items under the technology competence. We can observe that the need for an improved technological infrastructure to support RFID infrastructure was the most important item $(M=2.79)$, while the employees' knowledge about RFID was the lowest in the rating $(M=1.95)$.

Moreover, there were also four items under the top management support, with the management interested in adopting RFID being the highest in the rating $(\mathrm{M}=3.82)$, while the management risk-taking was the lowest in the rating $(\mathrm{M}=3.40)$. Furthermore, the last organizational characteristic,

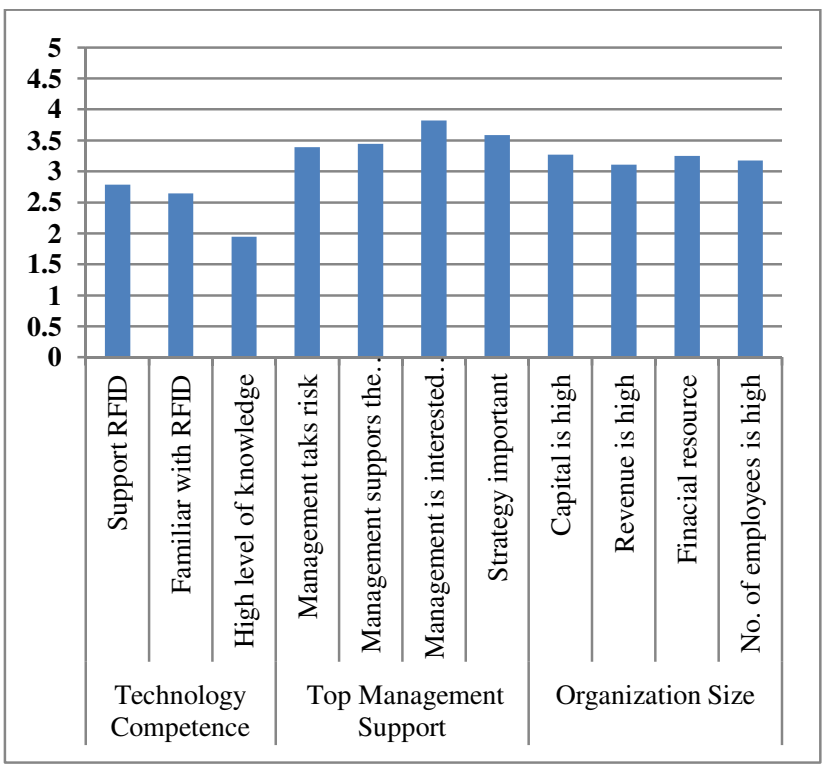

Figure 6. ORGNIZATIONAL CHARACTERISTICS 
the organization size, had four items. Fig. 6 indicates that the presence of a high capital within the firm was the highest in the rating $(M=3.27)$, while the revenue of the firm was the lowest in the rating $(\mathrm{M}=3.11)$.

\section{G. Environmental characteristics}

The following environmental characteristics were assessed: information intensity, competitive pressure, government regulation and social issues. There were four items under information intensity and high intensity, which were classified as the highest in the rating $(M=3.38)$, while the product and ordering complexity were at the lowest level in the rating $(\mathrm{M}=2.95)$.

Moreover, there were also three items under the competitive pressure that were classified as the highest in the rating $(\mathrm{M}=2.27)$, while the use of RFID by competitors was the lowest in the rating $(\mathrm{M}=1.88)$.

Furthermore, government regulation characteristic had three items, with the government policy having the highest position in the rating $(\mathrm{M}=3.27)$, while the government encouragement in the surveyed companies was at the lowest level in the rating $(M=2.80)$. Finally, privacy and security as a social issue was also the highest in the rating $(\mathrm{M}=3.66)$. In contrast, the lowest in the rating $(\mathrm{M}=2.42)$ was the use of RFID in the future.

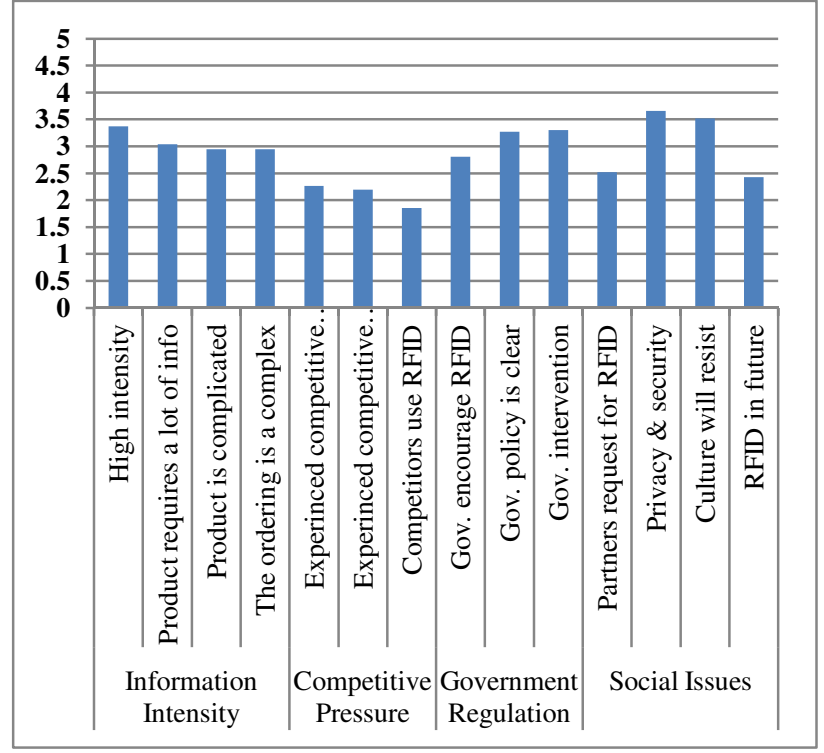

FIGURE 7. ENVIROMWNTAL CHARACTERISTICS

\section{H. RFID benefits from the survey respondents}

All the respondents are aware of RFID technology. Moreover, they believed that RFID was better than the barcode technology, even though they were not interested in replacing the latter by the former. They want to see RFID technology adopted and used in the public sector - that is, supported by the government - before indulging in it. Fig. 8 shows that all RFID elements were above $80 \%$, which means that getting oneself equipped with RFID in the retail sector is very beneficial. Following data analysis, the inventory management appeared to be the highest in the rating $(88 \%)$, while information accuracy in decision-making was the lowest $(81 \%)$.



FIGURE 8. RFID BENEFITS

\section{Adoption of RFID technology solution in the past}

RFID technology is still a new technology in Saudi Arabia, so it is rare to find a single company using it. From the survey, only one company used RFID technology for employees' attendance two years ago. Fig. 9 indicates that only $9 \%$ of the respondents have previously purchased an RFID technology solution. Indeed, one surveyed company has used RFID before, and therefore appears to be the first Saudi company to use an RFID technology solution in the retail industry. It can be concluded that a significant percentage of people $(91 \%$ of respondents) have not used RFID before. Consequently, Saudi companies are not familiar with RFID and need more time to adopt this technology.

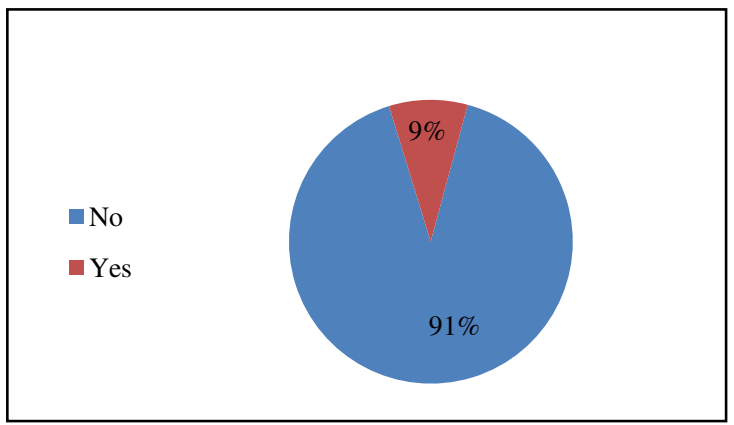

FiguRE 9. PREVIOUSLY PURCHASEd AN RFID TECHNOLOGY 


\section{J. Adoption of RFID technology solution in a near future}

The Saudi economy has grown rapidly, supported by oil. Thus, all Saudi companies have ambitious plans to improve and develop their services. Fig. 10 indicates that $30 \%$ of the respondents from the surveyed firms are looking forward to adopting RFID solutions in the near future, whereas $70 \%$ of them do not expect to adopt the technology. Yet, it is at least a good indication that within five years, the number of companies seeking RFID adoption will significantly increase from less than $1 \%$ to $30 \%$.

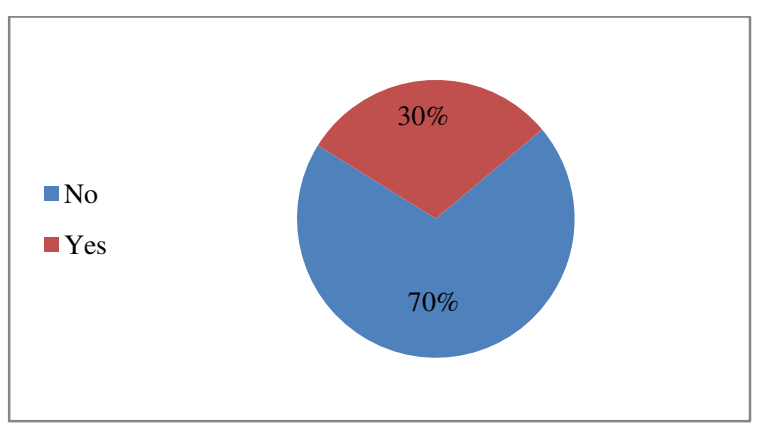

FIGURE 10. THE PLANNING TO PURCHASE AN RFID TECHNOLOGY SOLUTION IN FUTURE

As shown in Fig. 5, the average relative advantage level of RFID is 4, which accounts for the level "agree" in the assessment. The finding is consistent with other research Fosso-Wamba et al. [14], who have shown that the companies are inclined to focus on the benefits of RFID — which include improved data accuracy and inventory management, as well as their track and trace capabilities. This is independent of whether they are adopting RFID or not.

Companies may lack confidence in the RFID system as they keep using bar code and see RFID as a new challenge. The research results show that the companies based in Saudi Arabia are aware of the possible issues related to RFID system adoption, such as its complexity-which is compared to the possible competitive and relative advantages from the adoption of the system. Such awareness has triggered their decisions to adopt RFID in the future. While companies continue to believe they lack technical capabilities for adopting the new technology, they will keep using the existing technologies, such as the bar-code [15]. This issue makes the relative advantage an insignificant discriminator of RFID adoption.

Concerning RFID complexity, issues such as RFID customization and high costs will continue to underpin the complexity of RFID adoption [15]. Thus, the complexity of RFID integration is a significant barrier to subsequent RFID adoption.

RFID compatibility characteristics, such as the facility to integrate RFID infrastructure with the existing firm hardware and software as well as IT culture, will continue to have an impact on firm decisions concerning RFID adoption. This research is also consistent with Brown and Russell [16] and Wang et al. [15]. If the current experiences of companies with their existing information systems are found to be compatible with RFID development, or if the RFID applications fit with the current information infrastructure, then the changes introduced by RFID will be consistent with the existing practices. This will create a positive understanding of RFID and therefore favorably facilitate RFID implementation.

When looking at the organizational characteristics, we can observe that all items related to the top management have very high scores, thus highlighting the importance of top management support in the implementation of open complex innovations such as RFID technology [16]. In addition, factors such as the technology competency to support RFID infrastructure, the ability of top management to take risk and place the technology into their strategic plan, the existence of resources (e.g., HR, capital) will continue to play an important role in the adoption decision process regarding RFID technology.

Finally, environmental characteristics such as high information intensity, high requirement of product in terms of information, government encouragement, clear government policy, government intervention, privacy and security, as well as cultural issues will continue to influence the decision process related to RFID adoption.

\section{CONCLUSION}

This project contributes to extend knowledge and ideas on the role of RFID technology in the retail industry, with a specific focus on the Kingdom of Saudi Arabia. In particular, this study focuses on technological-organizational and environmental characteristics related to RFID adoption intention in the Saudi retail Industry. Contributions of our research include a development of a critical analysis and documentation on the introduction of RFID in the supply chain in the Saudi retail industry, and the impacts and outcomes of adopting this technology. Additionally, it is important to understand the most important characteristics of RFID adoption which condition a successful adoption of the technology in the retail industry in general, and more specifically in Saudi Arabia's environment. The results of this study specify a number of technological, organizational and environmental characteristics that will play an important role in the adoption decision process for RFID technology. The said set of characteristics may serve as a checklist for managers exploring the potential of RFID technology as well as a base for researchers working on RFID technology.

Even if this study offers some insights into technological, organizational and environmental characteristics that may influence the decision to adopt RFID within the Saudi retail industry, the sample of organizations is restricted to seven. Another drawback resides in the fact that the scope of the study largely depends on basic descriptive analysis. Future research should include model testing using complex statistical analyses such as regressions based on a robust sample. Also, the exploration of key contingency factors of RFID-enabled business value creation and realization in the retail sector in particular, and of RFID-enabled business value creation and realization in general, should also be included in future research [17]. Finally, the exploration of the potential of RFID- 
enabled improved intra- and inter-organizational decision making should be included in future research.

\section{REFERENCES}

[1] S. Fosso Wamba, L. A. Lefebvre, Y. Bendavid, and É. Lefebvre, "Exploring the impact of RFID technology and the EPC network on mobile B2B eCommerce: A case study in the retail industry," International Journal of Production Economics, vol. 112, pp. 614-629, 2008.

[2] S. Fosso Wamba, "Positioning RFID Technology into the Innovation Theory Landscape: a Multidimensional Perspective Integrating Case Study Approach " in The 15th Pacific Asia Conference on Information systems (PACIS). Brisbane, Australia, 2011.

[3] E. Bottani and A. Rizzi, "Economical assessment of the impact of RFID technology and EPC system on the fastmoving consumer goods supply chain," International Journal of Production Economics, vol. 112, pp. 548-569, 2008.

[4] D. Delen, B. C. Hardgrave, and R. Sharda, "RFID for better supply chain management through enhanced information visibility," Production and Operations Management, vol. 16, pp. 613-624, 2007.

[5] S. S. Al-Gahtani, "Computer technology acceptance success factors in Saudi Arabia: an exploratory study," Journal of Global Information Technology Management, vol. 7, pp. 5-29, 2004.

[6] CIA, "The World Factbook," 2010.

[7] Business Monitoring International, "Saudi Arabia Retail Report Q2 2010," 2010.

[8] R. T. Watson, S. Akelsen, and L. F. Pitt, "Building Mountains in that Flat Landscape of the World Wide Web," California Management Review, vol. vol. 40, pp. pp. 36-56., 1998.

[9] G. Graham and G. Hardaker, "Supply-chain management across the Internet.," International Journal of Physical Distribution \& Logistics Management vol. vol 30, pp. pp. 286-295., 2000.
[10] K. A. Patterson, C. M. Grimm, and T. M. Corsi, "Adopting new technologies for supply chain management," Transportation Research Part E: Logistics and Transportation Review, vol. vol. 39, pp. pp. 95-121, 2003.

[11] E. M. Rogers, Diffusion of Innovation. New York: Free Press, 2003.

[12] M. Bhattacharya, C. H. Chu, and T. Mullen, "A comparative analysis of RFID adoption in retail and manufacturing sectors," presented at in Proceeding of Conference on RFID, The Venetian, Las Vegas, Nevada, USA, 2008.

[13] P. Hadaya and R. Pellerin, "Determinants of Manufacturing SMEs Use of Web-based IOISs to Share Inventory Information with their Key Customers," in Actes $d u$ Congrès international sur le eCommerce et Gouvernance de l'Internet. Tunis, Tunisia, 2007.

[14] S. Fosso-Wamba, B. Keating, T. Coltman, and K. Michael, "RFID Adoption Issues: Analysis of Organizational Benefits and Risks," Wollongong University, vol. http://ro.uow.edu.au/infopapers/821, 2009.

[15] Y. Wang, Y. Wang, and Y. Yang, "Understanding the determinants of RFID adoption in the manufacturing industry," Technological Forecasting and Social Change, vol. vol. 77, pp. pp. 803-815, 2010.

[16] I. Brown and J. Russell, "Radio frequency identification technology: An exploratory study on adoption in the South African retail sector," International journal of information management, vol. Vol. 27, pp. pp. 250-265, 2007.

[17] S. Fosso Wamba and A. T. Chatfield, "A contingency model for creating value from RFID supply chain network projects in logistics and manufacturing environments," European Journal of Information Systems, vol. 18, pp. 615636, 2009. 